\title{
Cutting Parameter Optimization Based on Experience and Rules
}

\author{
Tao Luo, Wu Zhao", ChunjingLuo, Tiantian Shi and Rui Wang \\ School of Manufacturing Science and Engineering, Sichuan University, Chengdu Sichuan Province First Ring Road, No. \\ 24, 610065, China
}

\begin{abstract}
To reduce cutting time and costs, an optimized model of cutting parameter is proposed. Constraints like lathe and cutting tool are fully considered. The objective function is aiming at the target of profit margins. Some empirical indexes are used in the constraints and the objective function since the special properties of cutting process. The Fuzzy Comprehensive Evaluation Method is used to build an evaluation model, which provides an evolutionary path for cutting parameter. The evaluation matrix $\mathrm{R}$ in the model is determined by operators who use the cutting parameter to cut. A cutting parameter database system of $\mathrm{B} / \mathrm{S}$ structure was developed by JAVA language based on the optimization model and helped a company improved profit margins successfully.
\end{abstract}

Keywords: Constraints, Cutting parameter, Database, Evaluation, Optimize, The profit margins.

\section{INTRODUCTION}

Cutting is the basis of mechanical manufacturing. Appropriate cutting parameter will improve production efficiency, processing quality, production profits and reduce production costs. The scholars all over the world have never been stopping to research the optimization of cutting parameter since TAYLOR in 1907 [1] proposed the problem. And a series of important progresses have been made in theory. Dozens of optimization models and solving methods were established. Here are some famous researches. TANDON established optimization model of cutting parameter with the highest production efficiency [2]. H. Juan made research on the relationships between cutting parameter (cutting speed, feed per tooth, and axial depth of cut) and tool life based on a polynomial network [3]. Reference [4] studied the relationship between material and cutting parameter. Othmani $\mathrm{R}$ made the prediction of the optimal values of cutting speed to minimize both time and cost of dye production in $2.5 \mathrm{D} \mathrm{NC}$ milling [5]. Xiaolong Li researched the relationship between cutting tools and cutting parameter [6]. References [7-10] used some algorithm like Genetic Algorithms and Particle Swarm Optimization to calculate cutting parameters. In China, Ni Qi-min formulated a fuzzy model for multi-objective optimization of machining parameter for end milling [11] Chen Zhitong proposed a new cutting parameter optimization model for single cutting pass process based on the statistics principle and analyzed in detail for solving the parameter coupling problem [12]. With the development of science and technology, computer technology is widely used in machining. A lot of countries established cutting database system to store the cutting data and information according to certain rules using the computer. So far, about 12 countries such as Germany, the

*Address correspondence to this author at the School of Manufacturing science and Engineering, Sichuan University, Chengdu Sichuan Province first ring road, No. 24, 610065, China; Tel: +8628 85405307;

E-mail: zhaowu@scu.edu.cn
United States, Sweden, United Kingdom, Japan, Norway, Belgium and Hungary, established more than 30 cutting database systems. CUTDATA and INFOS are the most famous cutting database systems. CUTDATA is the world's first metal cutting database which contains a large number of cutting test data and can provide cutting parameter for more than 3750 species of materials, 22 kinds of processing methods and 12 kinds of cutting tool materials. German established INFOS in 1971. The INFOS stores more than two million materials information. It is the most complete cutting database system and its service ability is the strongest [13]. Here are a lot of studies about how to establish a cutting parameter database system. Reference [14] proposed a cutting parameter database system which can optimize cutting parameter. Reference [15] proposed a cutting database system which can optimize turning cutting parameter. But there were two shortages in the existing models and database system:

- The existing models did not include empirical indexes. Many factors in the process of machining at present could not be accurately controlled and quantized. So the empirical indexes gotten from experts and operators should be taken into consideration when people establish an optimized model of cutting parameter. They can improve the practicability of cutting parameter significantly.

- $\quad$ The existing cutting parameter database systems did not include an evaluation model of chosen cutting parameter. Because due to not enough refining of processing conditions, the existing cutting database provides only feasible data, not the optimal cutting parameter. It is necessary to set up an evaluation model to get the optimal cutting parameter.

In this paper, after interviewing cutting tools manufacturers and enterprise operators and professors in the university, a cutting parameter database system was established based on experience and rules, and the Fuzzy 
Comprehensive Evaluation model was used to establish an evaluation model for cutting parameter which provided an evolutionary way for cutting parameter.

\section{THE OPTIMIZATION MODEL OF CUTTING PARAMETER}

\subsection{The Influencing Factors of Cutting Parameter Selection}

Workpiece are made of a large number of different materials. Each material has its own unique features because of the influence of alloying elements, heat-treatment patterns and hardness. And this greatly affected the selection of cutting parameter. So the material grades, hardness index, heat-treatment pattern, and the tensile strength must be taken into consideration when selecting cutting parameter.

In order to improve profit margins, extending cutting tools' life is important. The three kinds of main cutting parameter, cutting speed, feed per tooth and cutting depth will influence the cutting tools' life, especially the cutting speed. The tool wear, and tool deformation are different with different structures and materials of cutting tools. And for some clip-type cutting tools, the model number of cutting tools will influence cutting parameter too. So, before choosing a cutting parameter, people must make sure which cutting tool will be used.

The traditional cutting parameter is used to manufacture rigid workpiece with simple structure, not fit for workpiece with weak rigidity and curved surface. Geometric features and mechanical properties of the workpiece have important influence on the cutting process. Before choosing a cutting parameter, serious deformation and vibration will appear if the structure is not considered in manufacturing weak rigid workpiece. So the features of workpiece are important when choosing cutting parameter.

Station-keeping ability, clamping ability and the biggest spindle torque, the biggest cutting power, the largest feed force provided by machine tool would influence cutting parameter directly. Designers should take machine tool information into consideration.

The cutting parameter must match the processing method and machining allowance of the procedure.

Finally, good cutting parameter should meet the requirements of surface roughness, shape and position accuracy of workpiece.

\subsection{Model for Cutting Parameter Optimization}

In the past, different optimization models of cutting parameter were established based on the actual production environment, and process conditions. In this paper, the objective function is aimed at the highest profit margins. A cutting parameter optimization model which takes all constraints into consideration was established. Because many factors in the process of machining at present could not be accurately controlled and quantized, this paper used some empirical indexes in the objective function and constraint conditions to reflect them. But because of not enough refining of processing conditions and the value of some empirical indexes were a scope, the cutting parameter was not good enough. People needed an evolutionary path for cutting parameter. The Fuzzy Comprehensive Evaluation model was used to build the evolutionary path. The operators mark each index in the evaluation matrix according to the result of processing after using cutting parameter, and computer would improve the priority of cutting parameter of high scores. The model for cutting parameter optimization is as shown in Fig. (1).

\subsection{Determination of Variables}

After the workpiece, cutting tool, machine tool are determined. The main factors which influence the production efficiency are cutting speed, feed per tooth, cutting depth (axial cutting depth) and cutting width (radial cutting depth). Operators get cutting depth and cutting width according to the requirement of machining allowance and the actual process. People don't need to optimize them and regard them as known. So this paper regard cutting speed $\left(\mathrm{v}_{\mathrm{c}}\right)$, and feed per tooth $\left(f_{z}\right)$ as variables.

\subsection{Determination of Constraints}

The following six constraints will determine the maximum and minimum values of cutting parameter after the workpiece, cutting tool, processing craft, processing system, and the requirements of quality are determined. There are some empirical indexes in the formulas.

Cutting speed constraint

$\pi \mathrm{DS}_{\min } / 1000 \leq \mathrm{v}_{\mathrm{c}} \leq \pi \mathrm{DS} \mathrm{max}_{\max } / 1000$

In the formula, $S_{\min }$ represents minimum spindle speed of machine tool; $S_{\text {max }}$ represents maximum spindle speed of machine tool.

Feed per tooth constraint

$\pi D V_{\text {Fmin }} / 1000 Z v_{c} \leq f_{z} \leq \pi D V_{F \max } / 1000 \mathrm{Zv}_{c}$

In the formula, $\mathrm{V}_{\mathrm{Fmin}}$ represents minimum feeding speed of machine tool; $\mathrm{V}_{\mathrm{Fmax}}$ represents maximum feeding speed of machine tool. $\mathrm{Z}$ represents number of teeth of cutting tool

The largest feed cutting force constraints.

$\mathrm{y}_{1}\left(\mathrm{v}_{\mathrm{c}}, \mathrm{f}_{\mathrm{z}}\right)=\mathrm{C}_{1} \frac{\mathrm{f}_{\mathrm{Z}}^{\mathrm{G}} \mathrm{a}_{\mathrm{e}}^{\mathrm{H}} \mathrm{a}_{\mathrm{p}}^{\mathrm{Q}}}{\mathrm{D}^{\mathrm{M}} \mathrm{v}_{\mathrm{c}}^{\mathrm{N}}} \mathrm{Z}<=\mathrm{F}_{\max }$

In the formula, $\mathrm{C}_{1}$ represents empirical coefficient; $G, H, Q, M, N$ represent empirical indexes; $F_{\max }$ represents the largest feed cutting force.

Processing power constraint

$\mathrm{y}_{2}\left(\mathrm{v}_{\mathrm{c}}, \mathrm{f}_{\mathrm{z}}\right)=\mathrm{C}_{2} \frac{\mathrm{f}_{\mathrm{Z}}^{\mathrm{G}} \mathrm{a}_{\mathrm{e}}^{\mathrm{H}} \mathrm{a}_{\mathrm{p}}^{\mathrm{Q}}}{\mathrm{D}^{\mathrm{M}} \mathrm{v}_{\mathrm{c}}^{\mathrm{N}-1}} \mathrm{Z}<=\mathrm{P}_{\max }$

In the formula, $\mathrm{C}_{7}$ represents empirical coefficient; $\mathrm{P}_{\max }$ represents the largest processing power.

Spindle torque constraints.

$\mathrm{y}_{3}\left(\mathrm{v}_{\mathrm{c}}, \mathrm{f}_{\mathrm{z}}\right)=\mathrm{C}_{3} \frac{\mathrm{f}_{\mathrm{z}}^{\mathrm{G}} \mathrm{a}_{\mathrm{e}}^{\mathrm{H}} \mathrm{a}_{\mathrm{p}}^{\mathrm{Q}}}{\mathrm{D}^{\mathrm{M}-1} \mathrm{v}_{\mathrm{c}}^{\mathrm{N}}} \mathrm{Z}<=\mathrm{T}_{\text {max }}$

In the formula, $\mathrm{C}_{3}$ represents empirical coefficient; $\mathrm{T}_{\max }$ represents the largest spindle torque. 


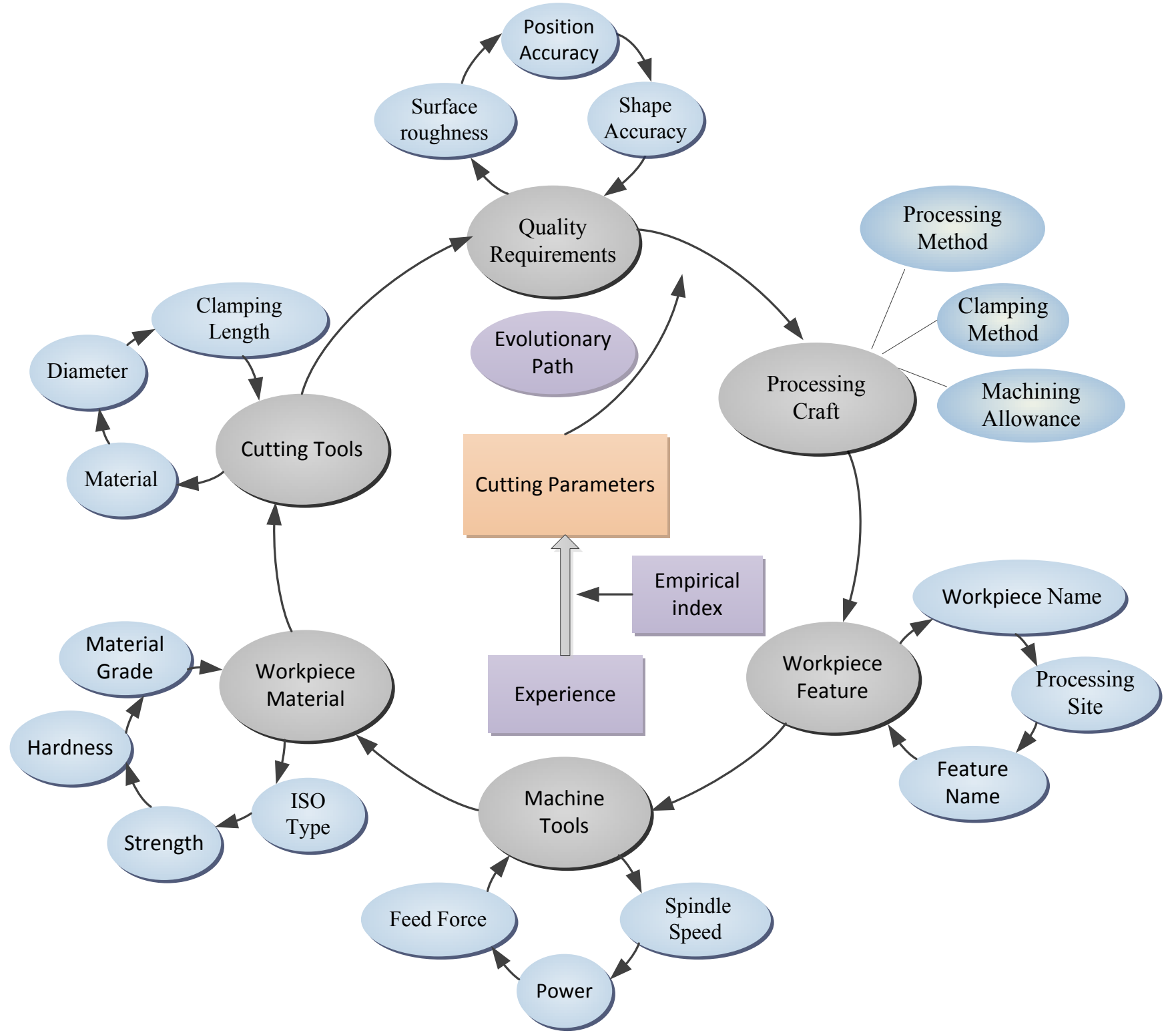

Fig. (1). Optimization model of cutting parameter.

Workpiece surface roughness constraints.

$\mathrm{y}_{4}\left(\mathrm{v}_{\mathrm{c}}, \mathrm{f}_{\mathrm{z}}\right)=\mathrm{C}_{4} \frac{\mathrm{f}_{\mathrm{z}}^{2}}{\mathrm{D}}<=\mathrm{R}_{\text {Amax }}$

In the formula, $\mathrm{C}_{4}$ represents empirical coefficient; $\mathrm{R}_{\mathrm{Amax}}$ represents the largest surface roughness.

\subsection{Determination of the Objective Function}

Manufacturing process is a technical and economic process. People use some technology to achieve other technology goals in order to benefit from the process. People want to get return when they put into something. The same for cutting process, different enterprises have the same goal called profit margins (the profits per unit time).

Production time per workpiece.

$\mathrm{M}_{1}\left(\mathrm{v}_{\mathrm{C}}, \mathrm{f}_{\mathrm{z}}\right)=\mathrm{T}_{\mathrm{A}}+\mathrm{T}_{\mathrm{B}}+\mathrm{T}_{\mathrm{C}} \mathrm{T}_{\mathrm{A}} / \mathrm{T}_{\mathrm{D}}$

$\mathrm{T}_{\mathrm{A}}=\pi(\mathrm{d}+\mathrm{p}) \mathrm{D} / 1000 \mathrm{Zv}_{\mathrm{c}} \mathrm{f}_{\mathrm{z}}$

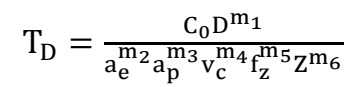

In the formula, $T_{A}$ represents cutting time; $T_{R}$ represents auxiliary time; $\mathrm{T}_{C}$ represents tool change time; $\mathrm{T}_{\mathrm{D}}$ represents cutting tool life; $d$ represents the length of workpiece; $p$ represents the total cutting depth; $\mathrm{C}_{0}$ represents empirical coefficient; $\mathrm{m}_{1}, \mathrm{~m}_{2}, \mathrm{~m}_{3}, \mathrm{~m}_{4}, \mathrm{~m}_{5}$ represent empirical indexes.

Cost per workpiece.

$M_{2}\left(v_{c}, f_{z}\right)=M_{1}\left(v_{c}, f_{z}\right) G_{1}+T_{A} G_{2} / T_{D}$

In the formula, $G_{1}$ represents cost of unit time; $G_{2}$ represents cost of material and grinding of cutting tool.

Profit margins.

$$
M_{3}\left(v_{c}, f_{z}\right)=\left[P_{W}-M_{2}\left(v_{c}, f_{z}\right)-G_{0}\right] / M_{1}\left(v_{c}, f_{z}\right)
$$

In the formula, $P_{W}$ represents price of workpiece; $G_{0}$ represents material cost. 
After constraint conditions and the objective function are determined, this paper uses GA (Genetic Algorithm) to calculate cutting parameter.

\subsection{The Evaluation Model}

Without evaluation indexes, the traditional cutting parameter database system did not have an evolutionary path for cutting parameter. An evaluation model which provided the way was built by the Fuzzy Comprehensive Evaluation model. The Fuzzy Comprehensive Evaluation model is a comprehensive evaluation method which uses the principle of fuzzy relationship synthetic to quantify some factors with fuzzy boundary. It quantifies the fuzzy indexes which reflect evaluated things by constructing grade fuzzy subset. Then it concludes all indexes by using fuzzy transformation principle. The main steps are as follows.

Determining the set of factors. $U_{m}$ represents the evaluation element.

$\mathrm{U}=\left\{\mathrm{U}_{1}, \mathrm{U}_{2}, \mathrm{U}_{3} \ldots \mathrm{U}_{\mathrm{m}}\right\}$

Determining the set of comments. $V_{n}$ represents the comment.

$\mathrm{V}=\left\{\mathrm{V}_{1}, \mathrm{~V}_{2}, \mathrm{~V}_{3} \ldots \mathrm{V}_{4}\right\}$

Determining the evaluation matrix. $r_{i j}$ represents the membership degree of Um to $V_{n}$.

$\mathrm{R}=\left(\mathrm{r}_{\mathrm{ij}}\right)_{\mathrm{m} * \mathrm{n}}$

Determining the weight vector. $A_{m}$ represents the proportion of evaluation elements.

$A=\left\{A_{1}, A_{2}, A_{3} \ldots A_{m}\right\}$

Determining the appropriate synthesis algorithm to calculate evaluation vector $\mathrm{B}$.

$\mathrm{B}=\mathrm{A} * \mathrm{R}$

In this paper, U, V, A for cutting parameter were got through interviewing experts in the universities and enterprises and cutting tool manufacturers like SANDVIK, URMA, KOMET, Dijet, WALTER.

$\mathrm{U}=$ sshape and position accuracy of workpiece, surface roughness of workpiece, cutting tool life, cutting deformation, cutting force .

$\mathrm{V}=\{$ very bad, bad, ordinary, good, very good $\}$.

$\mathrm{A}=\{0.2,0.3,0.25,0.1,0.15\}$.

For the determination of evaluation matrix $\mathrm{R}$, a combo box was set for each evaluation element $U_{m}$ in the system. The operators should choose a comment after using cutting parameter. Then the server responds with the corresponding $r_{i i}$ plus one. The matrix $\mathrm{R}$ will be more precise if the amount being used by people is bigger. Besides, each line of $\mathrm{R}$ needs to be normalized.

In order to make full use of evaluation vector B, this paper uses a column vector called $\mathrm{C}$ to take $\mathrm{U}$ and $\mathrm{B}$ into comprehensive consideration.

$\mathrm{C}=(3,4,5,6,7)^{\mathrm{T}}$ Then:

In this paper, dot product is used as synthesis algorithm.

$$
\begin{aligned}
& \mathrm{B}=\mathrm{A} * \mathrm{R}=(0.2,0.3,0.25,0.1,0.15)\left[\begin{array}{ccc}
\mathrm{r}_{11} & \cdots & \mathrm{r}_{15} \\
\vdots & \ddots & \vdots \\
\mathrm{r}_{51} & \cdots & \mathrm{r}_{55}
\end{array}\right]= \\
& \left(\mathrm{b}_{1}, \mathrm{~b}_{2}, \mathrm{~b}_{3}, \mathrm{~b}_{4}, \mathrm{~b}_{5}\right) \\
& \mathrm{P}=\mathrm{B} * \mathrm{C}=\left(\mathrm{b}_{1}, \mathrm{~b}_{2}, \mathrm{~b}_{3}, \mathrm{~b}_{4}, \mathrm{~b}_{5}\right) *(3,4,5,6,7)^{\mathrm{T}}
\end{aligned}
$$

$\mathrm{P}$ is a real number. It represents the cutting result of chosen cutting parameter. The priority of cutting parameter is higher if the value of $\mathrm{P}$ is bigger.

\section{CUTTING PARAMETER DATABASE SYSTEM}

\subsection{The System Flow}

There are three kinds of roles, administrators, common users, and senior users in the system. Common users are cutting operators. They use the system to choose appropriate cutting parameter. First, they choose constraints, then search and get cutting parameter. After cutting, they should evaluate the cutting parameter. The administrator's work is to maintain information. Senior users always are experts who need to check cutting parameter. The flow is as shown in Fig. (2).

\subsection{System Architecture}

The system is based on software of $\mathrm{B} / \mathrm{S}$ structure developed by JAVA language and can be easily deployed to Windows, Linux, HP-Unix, and IBM-Aix. The system is divided into three layers (view layer, business logic layer and data persistence layer). VIEW layer is used to display data and receive input from users. It is for interaction. Business logic layer is used to handle business logic and implement system design related to business needs, such as making rules for business, business process implementation, etc. It is the core value of system architecture. Data persistence layer is used to handle affairs (e.g. accessing database, CRUD operations etc.). Some open source components were used in the system. They are as shown in the Fig. (3).

\subsection{Database Design}

This paper used MySQL to store data because it is fast, and can be maintained easily and the volume of MySQL is small. In the database design, this paper used Navicat Premium and Power Designer to build the object relationship in the database. Before developing the database, this paper did the work about information collection, classification and organization, and then created effective tables by analyzing relationship between relevant data. Designer needs to find out the core data and the structure of tables before creating tables and then used the Power Designer to build UML model according to the relationship of entity one to one correspondence with data table as well as inner relationship of entity.

In the cutting parameter database, cutting parameter table is the core table. There are some relevant tables in the database, such as cutting blade table, cutter body table, workpiece material table, workpiece table, cutting medium table, and machine tool table. Appropriate major key and foreign key were set in each table. 


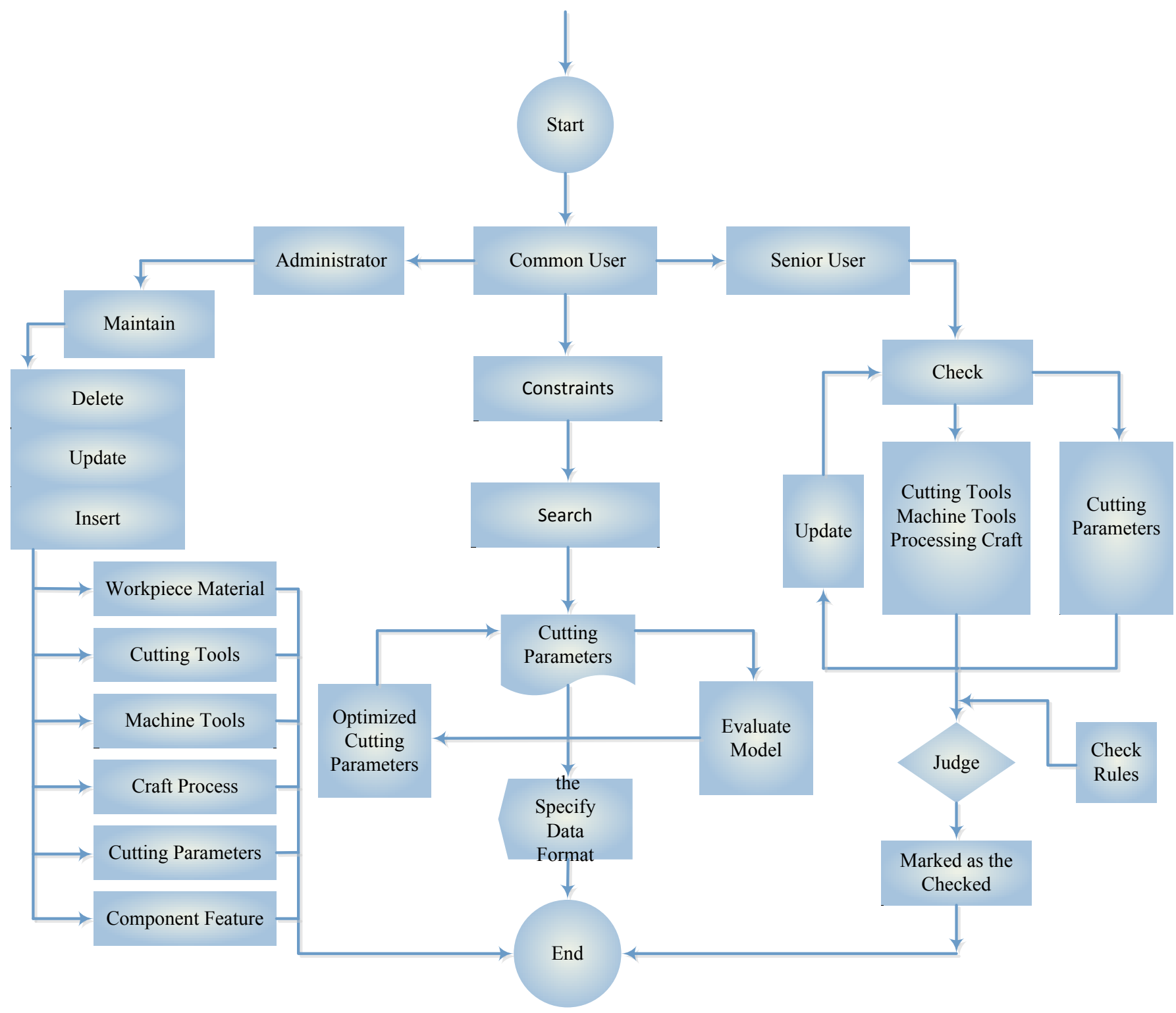

Fig (2). Cutting parameter database system flow.

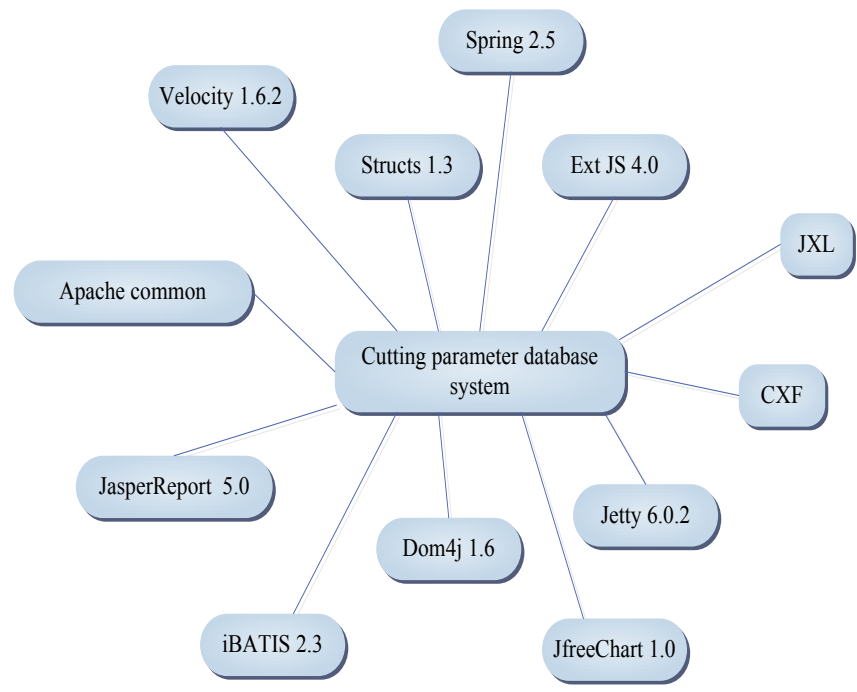

Fig (3). Open source components.

\subsection{System Interface}

The browser side development scheme of this system mainly included the Ext JS library, the custom tag library, report (Excel, Applet, PDF), chart (Flash, JFreeChart), controls interaction, and technologies about HTTP uploads and downloads. Ext JS V 4.0 is used for JavaScript language. The system interface is as shown in Fig. (4).

A company improves processing efficiency successfully and reduces processing costs by using the cutting parameter database system. The profit margins increased.

\section{CONCLUSION}

According to the actual production situation and experts' advices, this paper proposes an optimization model of cutting parameter, which describes requirements of choosing cutting parameter quantitatively, and qualitatively describes constraints on cutting speed $\left(\mathrm{v}_{\mathrm{c}}\right)$ and feed per tooth $\left(\mathrm{f}_{\mathrm{z}}\right)$. The 


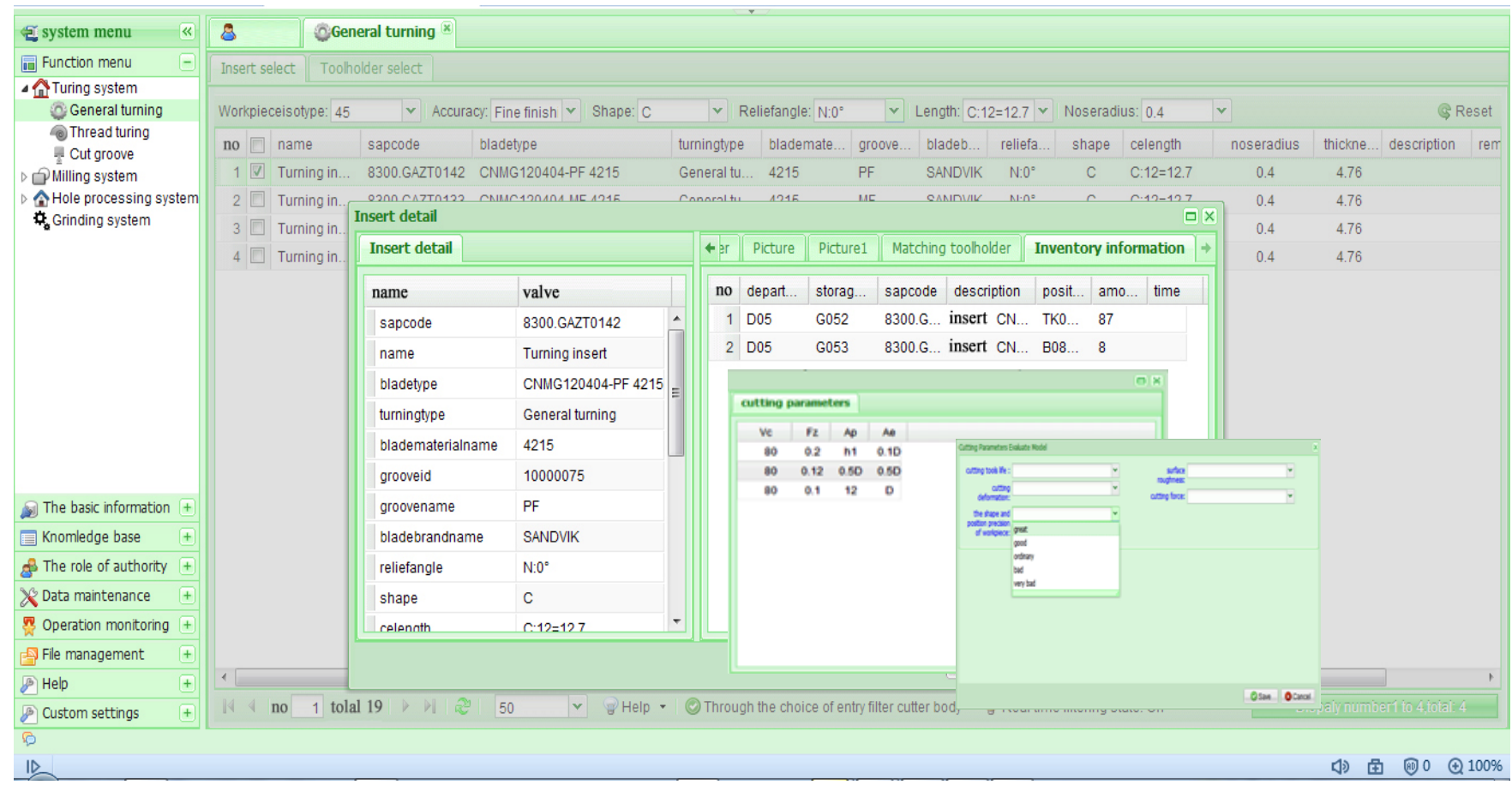

Fig (4). Cutting parameter database system interface.

objective function is aimed at the highest profit margins. The Fuzzy Comprehensive Evaluation model is used to build an evaluation model, which provides an evolutionary path for cutting parameter. Then a cutting parameter database system is established based on the optimization model by Java language.

However, since the constraints and the objective function are very complicated, this paper used Genetic algorithm to calculate. It is not very accurate. Future work can be done to research on some other algorithm for the optimization model.

\section{CONFLICT OF INTEREST}

The authors confirm that this article content has no conflict of interest.

\section{ACKNOWLEDGEMENTS}

This work was supported in part by NSFC (National Natural Science Foundation of China) under Grant No.51175357, and Sichuan Province Science and technology support program under Grant No. 2014GZ0114. Gratitude is also extended to the reviewers and the Editor for their valuable comments.

\section{REFERENCES}

[1] F. W. Taylor, "On the art of cutting metals," Transactions of $A S M E$, vol. 28, pp. 31-35, 1907.

[2] V. Tandon, H. El-Mounayri, and H. Kishawy, "NC end milling optimization using evolutionary computation," International Journal of Machine Tools and Manufacture, vol. 42, no. 5, pp. 595-605, 2002.
[3] H. Juan, S. F. Yu, and B. Y. Lee, "The optimal cutting-parameter selection of production cost in HSM for SKD61 tool steels," International Journal of Machine Tools and Manufacture, vol. 43, no. 7, pp. 679-686, 2003.

[4] T. M. El-Hossainy, A. A. El-Zoghby, M. A. Badr, K. Y Maalawi, and M. F. Nasr, "Cutting parameter optimization when machining different materials," Materials and Manufacturing Processes, vol. 25, no. 10, pp. 1101-1114, 2010.

[5] R. Othmani, M. Hbaieb, and W. Bouzid, "Cutting parameter optimization in NC milling," The International Journal of Advanced Manufacturing Technology, vol. 54, no. 9-12, pp. 1023-1032, 2011.

[6] X. Li, W. Zhao, C. Wang, Y. Zheng, and J. Zeng, Journal of Chemical and Pharmaceutical Research, vol. 6, no. 4, pp. 465473, 2014.

[7] T. J. Ko, and H. S. Kim, "Autonomous cutting parameter regulation using adaptive modeling and genetic algorithms," Precision Engineering, vol. 22, no. 4, pp. 243-251, 1998.

[8] J. Xi, and G. Liao, "Cutting parameter optimization based on particle swarm optimization," In Intelligent Computation Technology and Automation, 2009. ICICTA'09. Second International Conference on, vol. 1, pp. 255-258, 2009.

[9] L. B. An, L. J. Feng, and C. G. Lu, "Cutting parameter optimization for multi-pass milling operations by genetic algorithms," Advanced Materials Research, vol. 160, pp. 17381743, 2011.

[10] M. A. Khan, A. S. Kumar, and A. Poomari, "A hybrid algorithm to optimize cutting parameter for machining GFRP composite using alumina cutting tools,' The International Journal of Advanced Manufacturing Technology, vol. 59, no. 9-12, pp. 1047-1056, 2012.

[11] Q. M. Ni, and C. X. Li, "Fuzzy Method Based Model for Multi Objective Optimization of Machining Conditions for End Milling," Journal of ShangHai JiaoTong University, vol. 35, no. 10, pp. 1531-1534, 2001.

[12] Z. T. Chen, and B. G. Zhang, "Mathematic Model on Cutting Parameter Optimization for Unit Cutting Process," Journal of Mechanical Engineering, vol. 45, no. 5, pp. 230-236, 2009. 
[13] Z. Q. Liu, C. Z. Huang, Y. Wan, and X. Ai, "Research State and Development Directions of Cutting Database," Computer Integrated Manufacturing System (China), vol. 9, no. 11, pp. 937-943, 2003.

[14] M. V. Ribeiro, and N. L. Coppini, "An applied database system for the optimization of cutting conditions and tool selection,"
Journal of Materials Processing Technology, vol. 92, pp. 371374, 1999.

[15] B. Y. Lee, Y. S. Tarng, and H. R. Lii, "An investigation of modeling of the machining database in turning operations,' Journal of Materials Processing Technology, vol. 105, no. 1, pp. $1-6,2000$.

(C) Luo et al.; Licensee Bentham Open.

This is an open access article licensed under the terms of the Creative Commons Attribution Non-Commercial License (http://creativecommons.org/licenses/by-nc/4.0/) which permits unrestricted, non-commercial use, distribution and reproduction in any medium, provided the work is properly cited. 